\title{
Eine herausragende Persönlichkeit der Wiener Psychiatrie ist nicht mehr
}

Eine ewig jung aussehende und dynamisch wirkende Frau Dr. Monika Christian hat am 14. Februar 2011 in ihrem 72. Lebensjahr den Kampf gegen ihr drittes Karzinom verloren. Dr. Christian war über Jahrzehnte ein fixer Bestandteil der Wiener Psychiatrie und ein tragendes Mitglied der Gründungsmannschaft der Psychopraxis. Ich hatte das Privileg diese außergewöhnliche Frau als Kind kennenzulernen und in der Folge als Medizinstudent Zugang zu einer weisen Ratgeberin zu haben, die im Zentrum der Wiener Universitätskliniken arbeitete.

Als promovierte Juristin war Dr. Monika Christian primär bekannt als kompetente Büroleiterin mehrerer Vorstände: Univ.Prof. Dr. Hans Hoff, Univ.-Prof. Dr. Peter Berner sowie Univ.-Prof. Dr. Hans-Georg Zapotocky. Im Rahmen dieser Tätigkeit arbeitete Frau Dr. Christian auch eng mit Univ.-Prof. Dr. Hans Strotzka zusammen, dem Gründungsvorstand der Uniklinik für Tiefenpsychologie und Psychotherapie sowie seinem Kollegen Univ.-Prof. Dr. Cornelius Kryspin-Exner und der Oberärztin Dr. Ruth Naske, die ihr alle lange freundschaftlich verbunden blieben.

Frau Dr. Christian war schon während ihrer Klinikzeit eine schillernde Persönlichkeit wie sie nur mehr in nostalgischen Texten über die Wiener Medizinische Schule zu finden ist. In ihrem Schaffen und Wesen zeichnete sie sich durch besondere Merkmale aus - wie etwa ihre Überzeugung, dass die Agenden der Psychiatrie wichtige Aufgaben einer modernen Gesellschaft darstellen und ernsthaft in der Öffentlichkeit diskutiert werden müssen; durch den aufopfernden und selbstlosen Einsatz für die Patienten ihrer Ärztemannschaft (und für viele der sich in Ausbildung befindenden Jungärzte der Klinik), die oft in ihrem Büro anzufinden waren auf der Suche nach menschlich und nicht nur sachlich vermittelter Seelentherapie; durch ihren Optimismus und ihr humorvolles Wesen; und schließlich durch den gelebten Stolz auf das Kulturgut unseres Landes und ihre große Begeisterung für Musik (sie heiratete in Hans Christian, der kurz nach ihr verstarb, einen Opernsänger).

Im Dezember 1997 nahm der von ihr sehr geschätzte und im Vorjahr verstor- bene Univ.-Prof. Dr. Hans-Georg Zapotocky (gemeinsam mit Univ.-Prof. Dr. Walter Pöldinger) die Einladung des Springer Verlags an die Psychopraxis ins Leben zu rufen. Die Zielrichtung der Zeitschrift ist auch heute noch einzigartig in unserem Sprachraum. Die Psychopraxis stellte für die seelenverwandten Zieheltern Dr. Christian und Prof. Zapotocky ein Forum dar, in dem sie ihr gemeinsames Weltbild, das geprägt war von humanistischen und religiösen Idealen, mit ihren respektiven beruflichen Expertisen und kulturellen Neigungen in Einklang bringen

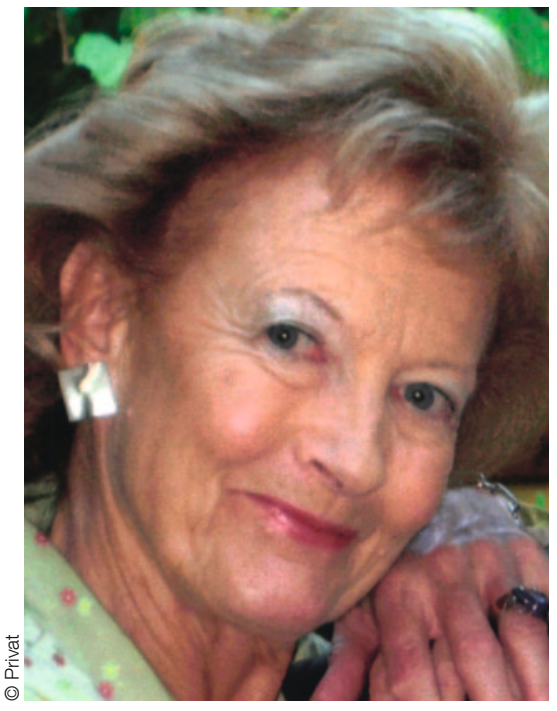

Dr. Christian war über Jahrzehnte ein fixer Bestandteil der Wiener Psychiatrie.

\section{Dr. Monika Christian}

konnten. Beide haben bis an ihr Lebensende große Freude am Heranwachsen der Psychopraxis erfahren und selbige mit Eifer verbreitet.

Als der Begriff eines „Mentors“ an der Universität Wien noch nicht verbreitet war, hatte ich dank Frau Dr. Christian die Gelegenheit im Studienjahr 1986/1987 mehrere Famulaturmonate mit den kreativsten Köpfen der damaligen Wiener Psychiatrie zu verbringen. Ihre Ratschläge über die fachliche Kompetenz ihrer Stations- und Ambulanzleiter waren kurz und bündig; Fakultätsmitglieder und Institutionen wurden treffend charakterisiert. Noch heute höre ich ihre wegweisende Bemerkung, „Du musst unbedingt mit dem Zapo (Prof. Dr.H.-G. Zapotocky) und in der Ambulanz arbeiten, da lernst du am meisten!". Als ich ihr später von einer Bewerbung um ein Stipendium in den USA erzählte, meinte sie in ihrer unnachahmbaren Art: „Das ist wunderbar, das musst du unbedingt machen. Geh' nach Amerika, da hast du sicher viele Möglichkeiten Karriere zu machen!" Sie verstand instinktiv, dass uneigennützig vorgetragener Rat nicht nur dem Empfänger dient, sondern auch dem Mentor Freude garantiert.

Während unseres letzten persönlichen Zusammentreffens 2010 bat mich Frau Dr. Christian um einen weiteren Beitrag für „ihre“ Zeitschrift. „Ich weiß, du hast viel $z u$ tun, aber vielleicht schaffst Du es für 2011." Angesprochen auf ihre Erkrankung und konfrontiert mit einem sorgfältigen vorgetragenen Bohren nach der eigenen psychischen Befindlichkeit antwortete sie ohne Zögern, „Na, ich werd' das schon hinkriegen, ist mir ja auch mit dem letzten Karzinom gelungen!" In den darauf folgendenen Telefonaten wurden von ihr mehrere Themen angesprochen, aber niemals die drohende Unheilbarkeit ihres metastasierenden Karzinoms.

Als charmante, dynamische und gebildete Österreicherin war Frau Dr. Monika Christian auch sehr unwienerisch. Während des mutigen Ankämpfens gegen ihre Erkrankung kam dieser Frau nie ein Laut des Selbstmitleids, der Frustration oder des Verzagens über die Lippen. Den um sie trauernden Familienmitgliedern, ihren Freunden und der Wiener Psychiatrie hat sie als Vorbild ein beeindruckendes Vermächtnis hinterlassen. Mit ihrem ansteckenden Optimismus würde Monika Christian uns sicher verordnen, dass wir zu dieser Stunde ihr Leben - und nicht ihr Ableben - feierlich begehen sollen. In diesem Sinne reiche ich in ewiger Dankbarkeit und in Bewunderung dieser außergewöhnlichen Frau meinen nächsten Beitrag zur Begutachtung ein.

Dr. Michael Schlossmacher, Associate Professor of Neurology and Cellular \& Molecular Medicine, University of Ottawa, Canada 